\title{
CORRIGENDUM
}

\section{Natto and viscous vegetables in a Japanese-style breakfast improved insulin sensitivity, lipid metabolism and oxidative stress in overweight subjects with impaired glucose tolerance - CORRIGENDUM}

Akiko Taniguchi-Fukatsu, Hisami Yamanaka-Okumura, Yuko Naniwa-Kuroki, Yuka Nishida, Hironori Yamamoto, Yutaka Taketani and Eiji Takeda

(First published online 8 March 2013)

doi:10.1017/S0007114511004156, Published by Cambridge University Press, April 2012.

The energy values in Table 2 in the paper by Taniguchi-Fukatsu et al. ${ }^{(1)}$ were incorrectly given. The correct values are given here.

The authors apologise for this error.

Table 2. Composition of the test meals

\begin{tabular}{lcll}
\hline & WR & \multicolumn{1}{c}{ Test meal } & \multicolumn{1}{c}{ Control meal } \\
\hline & WR $(200 \mathrm{~g})$ & WR $(200 \mathrm{~g})$ & WR $(200 \mathrm{~g})$ \\
& - & Natto $(50 \mathrm{~g})$ & Boiled soyabeans $(50 \mathrm{~g})$ \\
& - & Japanese yam $(60 \mathrm{~g})$ & Potatoes $(60 \mathrm{~g})$ \\
& - & Okra $(40 \mathrm{~g})$ & Broccoli $(40 \mathrm{~g})$ \\
& - & Soya sauce $(6 \mathrm{~g})$ & Soya sauce $(6 \mathrm{~g})$ \\
Energy $(\mathrm{kJ})$ & Water $(200 \mathrm{ml})$ & Water $(200 \mathrm{ml})$ & Water $(200 \mathrm{ml})$ \\
Carbohydrate $(\mathrm{g})$ & 1264 & 1912 & 1904 \\
Protein $(\mathrm{g})$ & 69.4 & 87 & 87.5 \\
Fat $(\mathrm{g})$ & 4.2 & 15.1 & 15.3 \\
Dietary fibre $(\mathrm{g})$ & 0.8 & 6.1 & 5.6 \\
$\quad$ Insoluble $(\mathrm{g})$ & 0.5 & 6.5 & 6.6 \\
Soluble $(\mathrm{g})$ & 0.5 & 4.7 & 5.5 \\
\hline
\end{tabular}

WR, white rice.

\section{Reference}

1. Taniguchi-Fukatsu A, Yamanaka-Okumura H, Naniwa-Kuroki Y, et al. (2012) Natto and viscous vegetables in a Japanese-style breakfast improved insulin sensitivity, lipid metabolism and oxidative stress in overweight subjects with impaired glucose tolerance. $\mathrm{Br} J \mathrm{Nutr}$ 107, 1184-1191. Published by Cambridge University Press, April 2012, doi:10.1017/S0007114511004156. 